\title{
FINISTERRA. BIOGRAFIA DE UMA REVISTA DE GEOGRAFIA (1966-2015)
}

\author{
MARIA JoÃo AlCOFORADO ${ }^{1}$ \\ Maria Fernanda Alegria ${ }^{2}$ \\ MARgarida QUEIRÓS ${ }^{2}$ \\ RicARDO A. C. GARCIA ${ }^{2}$ \\ Paulo Morgado ${ }^{2}$ \\ RUTE VIEIRA ${ }^{3}$
}

\begin{abstract}
O mundo está agora enleado nas malhas dum equipamento técnico sem precedentes na história. Os benefícios que isto traz para o próprio conhecimento do Globo são cada vez mais evidentes e a Geografia deles largamente está aproveitando. [..]Cada vez é mais necessário que a gente de reflexão se aplique com argúcia em alcançar uma perspectiva de compreensão, de tolerância e de equidade, de que, no meio de perigosas incertezas e de terríveis antinomias, o nosso tempo tanto carece.
\end{abstract}

(Orlando Ribeiro, Orientação, Finisterra, 1, 1966, p. 9)

RESUMO - Com a publicação do número 100, celebram-se os 50 anos de Finisterra. Revista Portuguesa de Geografia (1966-2015). Neste texto biográfico, depois de um breve enquadramento, que situa o nascimento da revista, reconstitui-se o percurso das suas estruturas organizativas desde o primeiro número, analisam-se os tipos de textos publicados ao longo do tempo e faz-se uma análise minuciosa e ilustrada dos artigos durante os 50 anos de existência (autores, espaços e temas tratados, idiomas, ilustrações). As principais fases do percurso da revista replicam de algum modo aspectos evolutivos da Geografia.

1 Directora da Finisterra e Investigadora do Centro de Estudos Geográficos (CEG), Instituto de Geografia e Ordenamento do Território (IGOT), Universidade de Lisboa. E-mail: mjalcoforado@campus.ul.pt

2 Membros da Comissão Executiva da Finisterra e Investigadores do CEG/IGOT/ULisboa. E-mail: mfalegria@netcabo.pt; margaridav@campus.ul.pt; rgarcia@campus.ul.pt; paulo@campus.ul.pt

3 Secretária da Finisterra e bolseira do CEG/IGOT/ULisboa. E-mail: rutevieira@campus.ul.pt 
A fase de lançamento (1966-1975) da Finisterra, concebida desde início como uma publicação internacional, acompanhou o aumento do número de geógrafos, bem como o confronto de ideias e de correntes de pensamento contemporâneo. No período seguinte, de consolidação (1976-1994), iniciaram-se alterações nas estruturas organizativas e no aspecto gráfico, ao mesmo tempo que se divulgavam novos temas de investigação geográfica. No período de alterações estruturais (1995-1999) criaram-se outros órgãos consultivos externos, novas normas de publicação e diferentes formas de apresentação dos textos. Pode dizer-se que se lançaram as bases para a fase seguinte, estandardização de procedimentos, internacionalização e difusão em acesso aberto (2000-2015). Nestes anos mantiveram-se as preocupações com o controlo de qualidade dos textos e o aumento da difusão da revista, agora facilitada pela era digital. Em todas as fases, foi determinante o papel dos revisores científicos, cujo empenho silencioso, anónimo e gracioso nos apraz destacar nesta celebração dos 100 números da Finisterra. Parafraseando Ruben A. "o geógrafo não cansa, avança”: são estas as perspectivas para a nova fase, que se iniciará em 2016.

Palavras-chave: Finisterra, CEG, Geografia, revista, divulgação, Portugal.

ABSTRACT - Finisterra. The Biography of a geographical journal (1966-2015). With the publication of the $100^{\text {th }}$ issue, Finisterra - the Portuguese Journal of Geography celebrates its $50^{\text {th }}$ anniversary (1966-2015). In this memoir, after a brief historical overview that begins with the creation of the journal, the organisational structures from the first issue onwards are reconstituted before moving on to conduct a thorough and illustrative analysis of the articles published over the 50 year existence of Finisterra. The main stages of the journal's journey somehow replicate the evolutionary aspects of Geography. The launch phase (1966-1975) of Finisterra, conceived from the beginning as an international publication, accompanied the increase in the number of geographers, and the confrontation of contemporary ideas and trends. The next period of consolidation (1976-1994), initiated with changes in structure and graphic layout, while simultaneously publishing new geographic research topics. In the period of structural change (1995-1999) other external advisory bodies, new standards of publishing and different ways of presenting texts were established. It can be said that these changes laid the foundation for the next phase, internationalisation and open access (2000-2015). In these years concerns remained with controlling the quality of texts and increasing the journal's dissemination, now facilitated by the digital age. At every stage, the role of scientific referees has been crucial, whose quiet, anonymous and gracious commitment we would like to highlight in this celebratory $100^{\text {th }}$ issue of Finisterra. Paraphrasing Ruben A. "The geographer does not give up, but moves forward": these are the prospects for the new phase, which will begin in 2016 .

Keywords: Finisterra, CEG, Geography, journal, dissemination, Portugal.

\section{ENQUADRAMENTO}

Em 1966 sai o primeiro número de Finisterra - Revista Portuguesa de Geografia, que mantém edição regular e ininterrupta desde então. Muito antes desse ano já Orlando 
Ribeiro pensava em criar uma revista do Centro de Estudos Geográficos (CEG), fundado por ele em Lisboa em 1943. Dessa ideia antiga dão testemunho alguns dos seus contemporâneos, bem como correspondência dirigida a amigos, de que é exemplo uma missiva para Jean Gottmann, de 5 de Setembro de 1943. 'L' année prochaine le Centre lancera une revue, qui serait très heureuse d'avoir votre collaboration. Nous publierons des articles sur la Géographie du Portugal et des colonies mais aussi sur des questions générales. Une revue des tendances de la géographie économique à l'heure actuelle serait du plus haut intérêt."

Em 1949, terminado o Congresso da União Geográfica Internacional, realizado em Lisboa por iniciativa de Orlando Ribeiro, e quando ainda não tinha sido possível lançar a revista, confessava em carta de 20 de Outubro de 1949 ao amigo Mariano Feio, futuro colaborador: "Se quisermos ultrapassar o quadro da investigação regional [entenda-se nacional], falta-nos bibliografia. A revista seria excelente meio de permuta que faz falta no nosso meio".

A publicação da revista iniciou-se em 1966. O nome "Finisterra" terá surgido a Orlando Ribeiro num passeio pela Galiza, já que a palavra sugere a extremidade ocidental do velho continente, "onde a terra acaba e o mar começa", no dizer de Camões ${ }^{\mathrm{ii}}$.

A vida do CEG e a da Finisterra são, desde o início, indissociáveis do percurso da licenciatura em Geografia da Universidade de Lisboa. Quando o CEG e a Finisterra foram criados, o ensino universitário de Geografia só existia em Lisboa e em Coimbra, com um número de alunos muito reduzido.

As revistas científicas com edição ininterrupta são raras em Portugal e no estrangeiro $^{\text {iii. }}$. A receptividade a diversas formas de pensar, interagir e trabalhar estava longe de ser regra em Portugal, mesmo no meio universitário. A criação de uma revista científica constituía um acto de coragem. Só uma pessoa decidida e com amplos horizontes se poderia abalançar a semelhante iniciativa. Abrir a ciência e os cientistas ao mundo, não se fechar sobre o País, era uma ideia cara a Orlando Ribeiro e aos outros dois fundadores da Finisterra. Suzanne Daveau tinha trabalhado e leccionado em França e em vários países africanos, e tinha um espírito livre e aberto a diferentes correntes de pensamento. Ilídio do Amaral, de origem angolana, estudou na Alemanha e tinha convívio frequente com geógrafos de outros países em diversas reuniões científicas internacionais. Assim, a Finisterra afirmar-se-ia, desde o primeiro número, como uma revista internacional, com a colaboração de franceses, italianos, espanhóis, alemães e brasileiros.

Mais tarde, quando a revista já era conhecida e prestigiada, discutiu-se, numa reunião dos investigadores do CEG, realizada pouco depois do 25 de Abril de 1974, se a Finisterra se deveria desdobrar em duas revistas especializadas tematicamente, separando a Geografia humana da física. Havia então quem defendesse a especialização geográfica, considerando ultrapassada a Geografia até então praticada. Essa separação constituía, para alguns, um sinal de mudança e de modernidade. Acabou por prevalecer a opinião de dar continuidade à revista que, no decurso dos 50 anos de existência assinalou publicamente vários aniversários (10, 30, 35 e, agora, 50 anos). 
Os primeiros 35 anos da Finisterra estão minuciosamente documentados por Ilídio do Amaral, no número temático sobre a "Paisagem", destinado a assinalar aquele aniversário (Amaral, 2001) iv. Dar-se-ão aqui mais pormenores sobre os últimos 15 anos e tentar-se-á fazer um balanço global, que possa ser útil aos futuros colaboradores nos vários órgãos da revista.

\section{ESTRUTURA ORGANIZATIVA E DIFUSÃO}

\section{Direcção e Secretariado}

A publicação de uma revista exige recursos vários e de natureza diversa que, no caso da Finisterra, revista não profissionalizada, se foram improvisando. Não é apenas a vontade de um cientista decidido e prestigiado como Orlando Ribeiro, que lhe consegue dar corpo. É grande a diversidade de tarefas e de funções para se manter a regular publicação de uma revista científica de qualidade. Para apoiar a Direcção foram sendo criadas outras estruturas, à medida das possibilidades do CEG e, também, da imaginação dos responsáveis mais directos da revista.

Quando a Finisterra nasceu, em 1966, havia apenas a Direcção, constituída por Orlando Ribeiro, Suzanne Daveau e Ilídio do Amaral, e como Secretários Carlos Alberto Medeiros e posteriormente Carminda Cavaco. A Fundação Calouste Gulbenkian, assegurou o apoio financeiro, que se manteve até 1980. Ilídio do Amaral e António Machado Guerreiro, responsável pela secretaria do CEG e licenciado em Românicas (1969) partilharam "as responsabilidades das acções práticas e burocráticas para a concretização do projecto" [a edição dos primeiros números da Finisterra] (Amaral, 2001: 15 iv). A partir de 1968, a preparação da revista foi, em grande parte, assegurada por Suzanne Daveau, sempre com a colaboração de Machado Guerreiro.

Os três fundadores asseguraram a Direcção de 1966 a 1975 (quadro I, 10 anos, 20 números) e, ainda, de 1976 a 1994, agora apoiados por Carlos Alberto Medeiros e Jorge Gaspar (mais 18 anos e 36 números). Em 1995 iniciou-se uma nova etapa, com um único Director, Carlos Alberto Medeiros, coadjuvado por uma Comissão de Redacção (1995-1999, 5 anos, 10 números). A partir de 2000 a direcção ficou a cargo de Maria João Alcoforado (2000 - 2015, 16 anos, 32 números).

Para apoiar a Direcção houve desde o início um ou mais "Secretários" (1966-1994). O secretariado foi substituído pela "Comissão de Redacção" (1995-2009) e, mais tarde, pela "Comissão Executiva” (desde 2010). Os membros do secretariado, com as suas várias designações posteriores, foram no geral bastante empenhados. Tinham interesses variados dentro do campo da Geografia e contribuíram, ao longo dos anos, com sugestões diversas para o desenvolvimento, a inovação e a difusão da revista. 
Quadro I - Membros da Direcção e do Secretariado da Finisterra (1966-2015).

Table I - Finisterra's Directors and different executive Committees (1966-2015).

\begin{tabular}{|c|c|c|}
\hline ANOS E No & DIRECÇÃO & SECRETÁRIOS (1966-1994) \\
\hline $1966-1971(1-6)$ & \multirow{2}{*}{ O. Ribeiro, S. Daveau, I. do Amaral } & C. A. Medeiros \\
\hline $1972-1975(7-20)$ & & C. Cavaco \\
\hline $1976-1980(21-30)$ & \multirow{7}{*}{$\begin{array}{l}\text { Os } 3 \text { fundadores, mais } \\
\text { C.A. Medeiros e J. Gaspar }\end{array}$} & A. M. Guerreiro \\
\hline $1981-1983(31-35)$ & & A. M. Guerreiro, J. Ferrão \\
\hline $1983-1985(36-38)$ & & A. M. Guerreiro, D. Abreu \\
\hline $1986-1988(39-45)$ & & A. M. Guerreiro, M. F. Alegria \\
\hline $1988-1990(46-50)$ & & A. M. Guerreiro, I. M. André, C. Patrício \\
\hline $1991(51-52)$ & & M. L. Rodrigues, C. N. Silva \\
\hline $1992-94(53 / 54-58)$ & & $\begin{array}{l}\text { M. J. Alcoforado }{ }^{v} \text {, N. M. Costa, M. L. Rodrigues, } \\
\text { C. Silva, J. L. Zêzere }\end{array}$ \\
\hline ANOS E No & DIRECÇÃO & COMISSÃO DE REDACÇÃO (1995-1999) \\
\hline $1995-1998(59 / 60-66)$ & \multirow{2}{*}{ C. A. Medeiros } & $\begin{array}{l}\text { M. J. Alcoforado (coord.), A. Lopes, } \\
\text { E. B. Henriques, M. Fragoso, S. Claudino }\end{array}$ \\
\hline $1999(67 / 68)$ & & $\begin{array}{l}\text { M. J. Alcoforado (coord.), C. Mora, E. Reis, } \\
\text { M. Queirós e P. Feio }\end{array}$ \\
\hline ANOS E No & DIRECÇÃO & COMISSÃO DE REDACÇÃO (2000-2009) \\
\hline $2000-2001(69-72)$ & \multirow{5}{*}{ M. João Alcoforado } & Idem sem a coordenadora, que passa a Directora \\
\hline $2002(73-74)$ & & $\begin{array}{l}\text { M. Queirós (coord.), C. Mora, E. Reis, } \\
\text { P. Morgado, P. Soares }\end{array}$ \\
\hline $2003-2004(75-78)$ & & $\begin{array}{l}\text { M. Queirós (coord.), H. Andrade, E. Reis, } \\
\text { P. Morgado }\end{array}$ \\
\hline $2005-2006(79-84)$ & & $\begin{array}{l}\text { M. Queirós (coord.), H. Andrade, P. Morgado, } \\
\text { G. Vieira, M. Neves }\end{array}$ \\
\hline $2007-2009(85-88)$ & & Idem mais M. F. Alegria \\
\hline ANOS E No & DIRECÇÃO & COMISSÃO EXECUTIVA (desde 2010) \\
\hline $2010-2013(89-95)$ & \multirow{3}{*}{ M. João Alcoforado } & $\begin{array}{l}\text { M. Queirós, M. F. Alegria, M. L. Rodrigues, } \\
\text { P. Morgado }\end{array}$ \\
\hline $2013(96)$ & & Idem mais Ricardo Garcia \\
\hline $2014-2015(97-100)$ & & $\begin{array}{l}\text { M. Queirós, M. F. Alegria, Paulo Morgado, } \\
\text { Ricardo Garcia }\end{array}$ \\
\hline
\end{tabular}

O quadro I mostra que, ao longo dos anos, muitos investigadores do CEG tiveram funções executivas na publicação da Finisterra. A Direcção tinha a seu cargo a orientação científica da revista, pugnando pela qualidade dos textos, pela sua divulgação no país e no estrangeiro e, em certas alturas, pela obtenção de financiamento. As tarefas de base de secretários/Comissão de Redacção/Comissão Executiva (conforme as diversas denominações) foram sendo ampliadas com o tempo, incluindo agora também a selecção e contactos com os revisores independentes, edição gráfica, gestão de plataformas digitais e a difusão da Finisterra. 


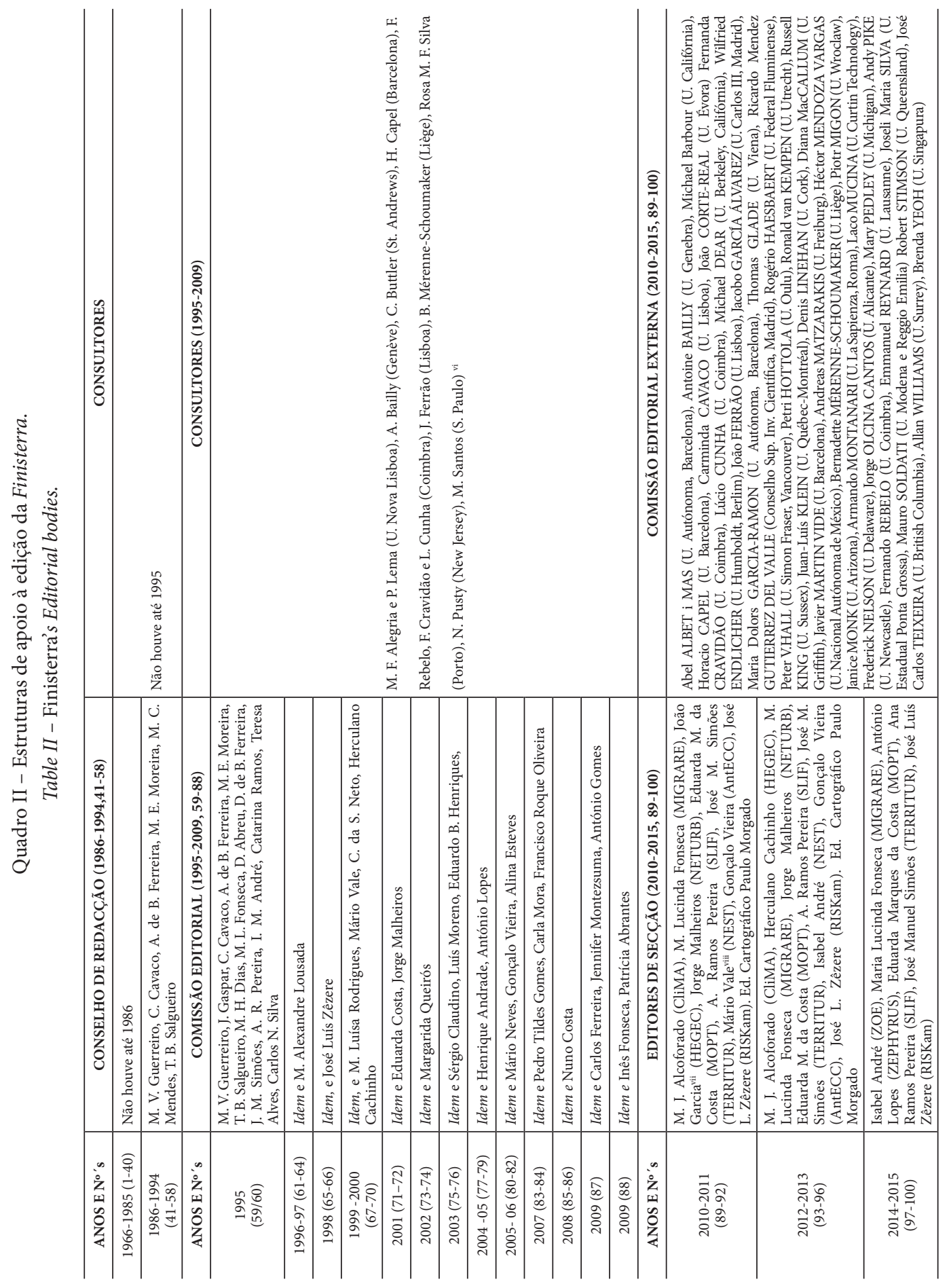




\section{Estruturas de apoio à edição}

A partir de 1986 a Direcção da Finisterra foi apoiada por outras estruturas (quadros II e III). O Conselho de Redacção começou por incluir apenas 6 investigadores mas, a partir de 1995, quando Carlos Alberto Medeiros passou a dirigir a revista, a Comissão Editorial (que substituiu o Conselho de Redacção) passou a agregar, de forma automática, todos os investigadores do CEG com doutoramento (quadro II). Com o tempo verificou-se que esta estrutura, criada com a intenção de implicar mais os investigadores do CEG na edição da revista, não era muito eficaz, acabando por manter-se apenas por inércia. Em 2010, após o reconhecimento formal de 10 "Núcleos de Investigação" pela Fundação para a Ciência e Tecnologia (FCT) decidiu-se que o coordenador de cada um deles passava a integrar os "Editores de Secção", designação que a partir desse ano substituiu a Comissão Editorial. A partir de 2014, os agora designados "Grupos de Investigação" reduziram-se para 7, continuando os coordenadores a fazer parte dos "Editores de Secção".

Com a direcção de Carlos Alberto Medeiros (1995), foi criada uma primeira "Comissão Editorial Externa" que incluía investigadores que não pertenciam ao CEG, cujos membros eram consultados sobre a qualidade dos textos, de acordo com o tema e a língua do artigo. A responsabilidade de publicação recaía fortemente sobre o Director e a Comissão de Redacção. Na década de 2000, foi iniciado o processo de revisão sistemático por pares e criada a figura de "Editor Responsável" por cada artigo. ${ }^{\text {ix }}$

Em 2010, os "Consultores" passaram a constituir a "Comissão Editorial Externa", que foi alargada (quadro II), passando a integrar maior número de investigadores estrangeiros. A decisão sobre a escolha dos seus membros foi tomada após consulta aos membros do CEG, que também foram envolvidos na decisão final, a qual foi aprovada pela Comissão Científica desta instituição. Sempre que o tema ou a língua do artigo assim o obrigaram, passaram a ser enviados artigos para revisão também a especialistas nacionais e estrangeiros, que não faziam parte destas comissões. A partir de 2010, a Finisterra passou a contar com uma Secretária. ${ }^{x}$

No que toca ao financiamento houve também alterações no decurso da vida da revista. Quando, em 1980, a Fundação Calouste Gulbenkian deixou de financiar a Finisterra, a sua sobrevivência foi complicada por mais 10 anos, tendo a situação melhorado em 1991-92, com o apoio da Faculdade de Letras da Universidade de Lisboa (quadro III). Entre 1993 e 1995, a Finisterra foi financiada pela Junta Nacional de Investigação Científica (JNICT) e a Fundação da Universidade de Lisboa, mas a revista ficou novamente sem apoio entre 1996 e 2000. A Biblioteca Nacional também apoiou pontualmente a Finisterra (quadro III). A partir de 2000, o financiamento do CEG passou a ser assegurado pela Fundação para a Ciência e Tecnologia, sendo votada anualmente, em Comissão Científica do CEG, uma verba para publicações, nas quais se inclui a Finisterra, que também dispõe de receitas próprias (assinaturas e vendas). Embora grande parte do trabalho para a edição da Finisterra seja feita a título 
gracioso por investigadores do CEG (principalmente os da Direç̧ão e Comissão Executiva da Finisterra) e pelos revisores (internos e externos), a Finisterra necessita de verba para despesas de edição, revisão profissional de textos em vários idiomas e ainda despesas de correio.

Quadro III - Instituições que financiaram a Finisterra (1966-2015).

Table III - Finisterra’s external financial sources (1966-2015).

\begin{tabular}{|c|c|}
\hline Anos e números & Instituições ${ }^{x i}$ \\
\hline $1966-1980(1-29)$ & Fundação Calouste Gulbenkian \\
\hline $1980-1990(30-50)$ & Sem apoio \\
\hline $1991-1992(51-53)$ & Faculdade de Letras da Universidade de Lisboa \\
\hline $1993-1995(55-60)$ & $\begin{array}{c}\text { Junta Nacional de Investigação Científica (JNICT); } \\
\text { Fundação da Universidade de Lisboa }\end{array}$ \\
\hline $1996-2000(56-60)$ & Sem apoio \\
\hline $2000-2001(70-71)$ & Fundação para a Ciência e Tecnologia (FCT) \\
\hline $2001(72)$ & $\begin{array}{l}\text { Fundação da Universidade de Lisboa; Faculdade de Letras; } \\
\text { Biblioteca Nacional }\end{array}$ \\
\hline $2002(73-74)$ & $\begin{array}{c}\text { Fundação para a Ciência e Tecnologia; } \\
\text { Biblioteca Nacional; } \\
\text { Faculdade de Letras da Universidade de Lisboa }\end{array}$ \\
\hline $2003-2004(75-78)$ & $\begin{array}{l}\text { Fundação para a Ciência e Tecnologia; } \\
\text { Faculdade de Letras da Universidade de Lisboa }\end{array}$ \\
\hline $2005-2015(79-100)$ & Fundação para a Ciência e Tecnologia \\
\hline
\end{tabular}

\section{Impressão e distribuição}

No decurso da sua já longa existência foram várias as tipografias onde a Finisterra foi impressa ${ }^{\text {xii }}$. Cumprindo uma das suas primeiras premissas, são feitas permutas com diversas revistas, além de ofertas a cientistas e instituições. Há também assinantes, quer a título particular, quer institucional. A situação em 2015 está registada no quadro IV. Embora a principal divulgação da revista impressa seja feita em Portugal, existem permutas e assinaturas de bibliotecas estrangeiras, nomeadamente de Espanha, França e Alemanha, que mantêm interesse em completar a colecção dos 100 números em papel, embora todos eles estejam disponíveis online desde 2010. 
Quadro IV - Número de permutas, assinaturas e ofertas da Finisterra.

Table IV - Number of exchanges, subscriptions and gifted copies of Finisterra.

\begin{tabular}{|c|c|c|c|c|}
\hline Países & Permutas & Assinaturas & Ofertas & Total \\
\hline Portugal & 24 & 32 & 30 & 86 \\
\hline Espanha & 18 & 2 & 7 & 27 \\
\hline França & 17 & 1 & 2 & 20 \\
\hline Alemanha & 16 & 1 & 1 & 18 \\
\hline Brasil & 6 & 4 & - & 10 \\
\hline Bélgica & 4 & - & - & 4 \\
\hline Reino Unido & 3 & 1 & - & 4 \\
\hline Itália & 3 & 6 & - & 9 \\
\hline Suíça & 3 & - & 1 & 4 \\
\hline Canadá & 2 & 1 & - & 3 \\
\hline Polónia & 2 & - & - & 2 \\
\hline Holanda & - & 1 & - & 1 \\
\hline EUA & 1 & 6 & 2 & 9 \\
\hline Outros & 15 (a) & 1 (b) & - & 16 \\
\hline TOTAL & 114 & 56 & 43 & 213 \\
\hline
\end{tabular}

(a) Angola, Áustria, Argentina, Cabo Verde, Colômbia, Costa Rica, Dinamarca, Equador, Eslovénia, Índia, Japão, México, Moçambique, Tunísia, Rússia; (b) Irlanda

A distribuição foi assegurada pela "Livraria Portugal" entre 1966-1988 (n. $\left.{ }^{\circ} 1-45\right)$ e pela "Livraria Arco Íris" entre 1988 e 1994 (46-58) $)^{\text {xiii }}$. A partir de 1995 (59/60), a distribuição passou a ser feita directamente pelo CEG. Antes da vulgarização da internet, a visibilidade científica da Geografia era às vezes assegurada pelos media, por questões de moda ou por acontecimentos ocasionais. É oportuno lembrar quanto a divulgação dos primeiros números da Finisterra deve ao escritor Rúben Andresen Leitão, mais conhecido por Ruben A., que fez sucessivas recensões aos primeiros números (1-10), entre 1966 e 1971 na rubrica "Livros Escolhidos" do Diário Popular. A 15 de Setembro de 1966, a propósito do lançamento do $1^{\circ}$ número da revista, Ruben A. escreveu: "A cultura portuguesa contemporânea não pode ficar indiferente ao aparecimento de uma revista deste calibre - facto que tem de ser devidamente assinalado, tanto no aspecto científico, como também nas múltiplas potencialidades que oferece ao leitor comum." Mais à frente acrescentava: "Há uma investigação feita no espaço e no tempo, regional e global e (...) que evoca tanto a posição europeia e mediterrânea de Portugal, como a sua posição no Globo." Nos anos seguintes, que antecederam o seu desaparecimento prematuro, Ruben A. vai dando conta do conteúdo dos diversos números da Finisterra, analisando em profundidade os artigos, sobretudo os mais orientados para a Geografia humana, deixando transparecer o seu entusiasmo por certas obras ou novas teorias. 


\section{Difusão online}

A mais ampla difusão registou-se devido à indexação em diversas plataformas, portais de informação, bases de dados e índices: Directory of Open Access Journals (DOAJ); SciELO, Dialnet, Latindex, EBSCO - Academic Search Complete, WebQualis (CAPES-A2). Em 2013, a revista passou a fazer parte da base de dados bibliográfica SCOPUS, privilegiada pela Fundação para a Ciência e Tecnologia (FCT), permitindo que os resumos, citações e artigos publicados sejam automaticamente agregados aos identificadores pessoais dos seus autores, em bases de dados internacionais. A importância destas bases de indexação no meio académico contribuiu para atrair mais autores, tendo aumentado o número de textos submetidos para publicação e o número de leitores. Em 2010, a Finisterra passou também a integrar as plataformas académicas, tal como a Academia.edu e a Researchgate e redes sociais como o Facebook.

Em 2011, completou-se o processo de digitalização da revista, desde o seu primeiro número, com disponibilização em acesso livre, na página electrónica do CEG. Em 2012, a Finisterra foi uma das 10 revistas portuguesas escolhidas para integrar o Repositório Científico de Acesso Aberto de Portugal (RCAAP), uma plataforma electrónica para gestão online dos artigos desde o processo de submissão até à publicação; está em funcionamento desde 2013 e constitui também um excelente motor de busca.

A partir de 2015, os artigos da Finisterra passaram a ter DOI (Digital Object Identifier), atribuído através da agência Cross-Reference ${ }^{\text {xiv }}$ e obteve-se a integração da Finisterra na Scielo Citation Index na Web of Science (Thomson Reuters).

\section{OS TEXTOS}

Analisa-se seguidamente a forma de apresentação dos textos, a evolução do número de páginas e o âmbito espacial e temático dos textos submetidos à Finisterra.

\section{Estrutura de apresentação e periodicidade}

Desde o primeiro número que a apresentação dos textos na revista é feita em várias secções, mas o seu tipo e número (artigos, notas, recensões, etc.) foi sendo modificada. A organização foi a mesma até 1994 (n. ${ }^{0}$ 58), alterando-se um pouco a partir de então (quadro V). Os artigos continuaram a figurar como primeira rubrica, mas as recensões ficaram separadas das notas a partir desse ano ${ }^{\mathrm{xv}}$, subdividindo-se as recensões em sínteses bibliográficas e actualizações bibliográficas. Desapareceram os elementos estatísticos e os documentos para o ensino, que até 1994 alternavam entre si, sendo substituídos por notícias.

A decisão de que as "notícias" passassem a substituir os "elementos estatísticos" e os "documentos para o ensino" teve a ver com a diminuição de submissões de textos dessa índole, talvez pelo facto do Instituto Nacional de Estatística ter passado a publicar os seus relatórios e por terem surgido revistas específicas para o ensino básico e secundário, 
nomeadamente a Apogeo, editada pela Associação de Professores de Geografia. Por outro lado, o número de reuniões científicas com participação de geógrafos do CEG aumentou de forma tão significativa, que se considerou útil criar uma secção específica para dar conta desses eventos.

$\mathrm{O}$ design da capa da Finisterra variou ao longo do tempo (quando V), mantendo sempre, no entanto, a esfera armilar. Inicialmente, esta destacava-se a preto, em fundo cinzento, num papel que deixou de se encontrar no mercado. Em 1995, foi composta nova capa por A. Lopes, então membro da Comissão de Redacção, utilizando o tema de um painel de azulejos do Palácio da Pena, conservando a esfera armilar. No decorrer do colóquio "Paisagem", em 2002, Pedro Calapez fez uma oferta inestimável à Finisterra e ao CEG: várias pinturas de sua autoria, a partir das quais se seleccionou uma para compor a capa que vigora desde 2003 (quadro V). Neste $100^{\circ}$ número da Finisterra, foi escolhida outra imagem das 7 anteriormente oferecidas. Toda a colecção será brevemente exposta nas novas instalações do CEG e do Instituto de Geografia e Ordenamento do Território (IGOT) ${ }^{\text {xvi }}$, em funcionamento desde o início do ano lectivo de 2015-16.

Quadro V - Tipologia dos textos na Finisterra e diferentes capas.

Table V-Typology of texts in Finisterra and different covers.

\begin{tabular}{|c|c|c|c|}
\hline ANOS E No & TIPOLOGIA DOS TEXTOS & \multicolumn{2}{|l|}{ CAPA $^{\mathrm{xVII}}$} \\
\hline $\begin{array}{c}1966-1994 \\
(1-58)\end{array}$ & $\begin{array}{c}\text { ARTIGOS } \\
\text { NOTAS E RECENSÕES } \\
\text { ELEMENTOS ESTATÍSTICOS } \\
\text { em alternância com } \\
\text { DOCUMENTOS PARA O ENSINO } \\
\text { Com índices temáticos e de autores por volume }\end{array}$ & $\begin{array}{l}\text { Esfera armilar sobre fundo } \\
\text { cinzento 1966-1991 (1-52) } \\
\text { (A mesma capa com outro } \\
\text { papel 1992-1994 (53-58)) }\end{array}$ & FINISTERRA \\
\hline $\begin{array}{c}1995-2015^{\text {xviii }} \\
(59 / 60-99)\end{array}$ & $\begin{array}{c}\text { ARTIGOS } \\
\text { NOTAS } \\
\text { RECENSÕES } \\
\text { 1. SínTESES BIBLIOGRÁfiCAS } \\
\text { 2. ACTUALIZAÇão BIBLIOGRÁFICA } \\
\text { Notícias } \\
\text { Deixam de figurar índices temáticos e de autores. } \\
\text { A partir de } 2012 \text { deixam de figurar NOTAS }\end{array}$ & $\begin{array}{c}\text { Painel de azulejos } \\
\text { (Composição: A. Lopes) } \\
\text { 1995-2002 } \\
(53 / 54-74) \\
\\
\\
\text { Esfera armilar sobre } \\
\text { fundo azul } \\
\text { (Pedro Calapez) } \\
\text { 2003-2015 } \\
\text { (75-99) }\end{array}$ & 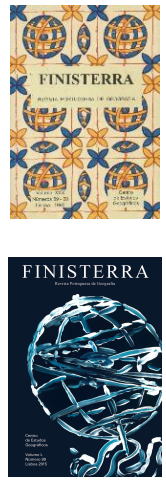 \\
\hline $\begin{array}{l}2015 \\
(100)\end{array}$ & ARTIGOS & $\begin{array}{l}\text { Esfera armilar sobre } \\
\text { fundo ocre } \\
\text { (Pedro Calapez) } \\
2015 \\
(100)\end{array}$ & FINIS \\
\hline
\end{tabular}


Ao longo do tempo, também se verificaram outras alterações. Os resumos foram localizados no início dos textos (1995), e passaram a apresentar-se títulos de figuras e de quadros na língua em que o texto era escrito e também em inglês (1995). A indicação das ligações institucionais dos autores passou para a página de rosto de cada artigo, com o respectivo endereço electrónico (1992). A periodicidade definida desde o início (um volume por ano, em dois números) tem sido cumprida. De 1966 a 1997 a numeração das páginas dos dois volumes do ano era seguida mas, a partir de 1998, os dois números do ano passaram a ter paginação independente. Foram editados 3 índices decenais (1966-1975), (1976-1985) e (1986-1995), com registo de todos os autores e classificação do conteúdo dos textos por autor, regiões e temas e, em 2002, foi divulgado um CD-Rom com índices por autor (1966-2000), no âmbito do Colóquio "Paisagem". Hoje em dia essa informação encontra-se disponível na página da revista no RCAAP.

\section{Número de páginas}

O total de páginas de cada número da revista e das dedicadas a artigos, tem oscilado bastante, embora se note que os primeiros números tinham dimensão menor e mais regular: entre cerca de 150 a 200 páginas, até ao início da década de 1980 (quadro VI). A partir de então os exemplares ultrapassam as 200 páginas, ou mesmo as 250 xix. As páginas dedicadas a artigos aumentaram nas duas últimas décadas, embora tenha diminuído o número de páginas por artigo (de cerca de 30 para uma média de 17), seguindo a tendência generalizada de apresentar artigos mais curtos (quadro VI).

Quadro VI - Número de páginas da Finisterra por artigos, por década.

Table VI - Number of pages per article, by decade.

\begin{tabular}{cccc}
\hline Década & Total pág. & Pág. de artigos & $\begin{array}{c}\text { Média pág. } \\
\text { por artigo }\end{array}$ \\
\hline $1966-1975$ & 2134 & 73 & 29 \\
$1976-1985$ & 1864 & 63 & 30 \\
$1986-1995$ & 2055 & 67 & 31 \\
$1996-2005$ & 2208 & 135 & 16 \\
$2006-2015$ & 2279 & 129 & 18 \\
\hline & 10540 & 467 & \\
\hline
\end{tabular}

\section{ARTIGOS}

Constituindo os artigos a secção principal da Finisterra, segue-se a sua análise sob diversos aspectos: controle de qualidade, autores, idiomas, resumos e tipo de ilustrações. Para não alongar demasiadamente o texto, as "Notas", apesar de frequentemente encerrarem temas de interesse, não foram comtempladas. 


\section{Controle de qualidade dos artigos}

Assegurar a qualidade dos textos publicados foi sempre um imperativo do qual a Finisterra nunca abdicou, mas a maneira de atingir esse propósito foi-se alterando. Até 1996 era principalmente a Direcção (com algum apoio da Comissão de Redacção com as suas diversas designações), que garantia a relevância dos manuscritos publicados. Posteriormente a qualidade dos textos passou a ser coadjuvada por "revisores científicos", ou seja, investigadores independentes considerados peritos no assunto, escolhidos em reunião da Direcção com a Comissão de Redacção (depois Comissão Executiva). A Direcção segue todo o processo de supervisão e responsabiliza-se pela decisão final (publicação ou recusa) e pela revisão das provas em colaboração com os autores. O elevado número de textos submetidos, bem como o tempo que decorre habitualmente entre a submissão e a publicação (ou recusa de edição) levou em 2014 a iniciar o processo por uma triagem prévia dos textos, a cargo da Direcção e da Comissão Executiva, com o apoio de um investigador do CEG perito na matéria, para decidir com maior rapidez os que se adaptam aos propósitos da revista e têm qualidade para serem enviados aos revisores científicos. No caso de não-aceitação dos artigos para revisão, os autores são assim rapidamente notificados, por carta da Direcção ou do Editor responsável, com a justificação da decisão tomada.

Os textos aprovados para revisão são enviados a dois revisores externos, tendo sido criadas fichas de avaliação para uma apreciação escrita e anónima, onde nem revisores nem autores têm conhecimento recíproco (double-blinded). Havendo pareceres contraditórios ou avaliações insuficientemente justificadas, os textos são enviados pela Comissão Executiva a um terceiro revisor. Desde 2013 é o "editor responsável" de cada artigo, no âmbito da Comissão Executiva, que se encarrega de seguir todo o processo desde a submissão à publicação.

O contributo dos revisores científicos é valiosíssimo para manter a qualidade. Dadas as inúmeras tarefas dos docentes universitários e especialistas a quem recorreremos, o trabalho de revisão é merecedor de grande gratidão por parte dos responsáveis da revista. Recebemos revisões muito pormenorizadas sobre aspectos de conteúdo, organização e forma dos artigos, que são de grande utilidade para a remodelação dos textos, e valiosas para os autores, mesmo que o artigo não seja aceite. Respeitando o anonimato, os nomes dos revisores científicos são publicados em conjunto, apenas de dois em dois anos.

A manutenção da qualidade científica e formal da revista implicou ainda outras iniciativas: a especificação de "normas de publicação", em português e inglês, com a normalização da dimensão e da apresentação dos textos e da bibliografia, a obrigatoriedade de figurarem resumos em vários idiomas, a inclusão de títulos de figuras e de quadros em inglês, etc. No número 81 (2006) foram efectuados alguns ajustes às nomas de publicação, que se mantiveram até 2013, data em que a Finisterra foi integrada no RCAAP. A plataforma permite gerir de uma forma mais eficaz o processo de avaliação, 
agilizando as tarefas da Comissão Executiva e dos Editores Responsáveis, assim como o contacto com os Autores.

\section{2. Âmbito espacial dos artigos}

Numa revista de Geografia tem interesse perceber quais as áreas geográficas a que é dada mais ou menos atenção e verificar se houve alterações no decurso do tempo. Para se analisar o âmbito espacial dos artigos partiu-se dos "índices regionais" que figuram nos 3 índices decenais publicados: 1966-1975, 1976-1985 e 1986-1995. Para os anos posteriores a 1995 mantiveram-se as mesmas divisões geográficas, com o objectivo de verificar a evolução. Mas tem de se reconhecer que não é fácil identificar os espaços geográficos aos quais a Finisterra tem dado mais ou menos atenção, por várias razões: há textos que não se referem a um espaço geográfico específico, como é o caso dos de índole teórica, dos de forte pendor metodológico, ou dos dedicados a pessoas ou instituições. Há também outros que se referem a espaços sem limites definidos.

Numa análise por país estudado, Portugal (não representado no mapa seguinte) ocupa o $1^{\circ}$ lugar. Vêm depois a Espanha, o Brasil, Angola e Moçambique (fig. 1a). No fundo, regista-se a orientação que Orlando Ribeiro pretendia: que a revista se consagrasse a temas portugueses, devendo ser também "uma janela aberta para o mundo" (Ribeiro, 1966).

De notar que a situação se alterou ao longo dos anos. Os artigos sobre Portugal ultrapassaram sempre 30 por década, atingindo valores mais elevados entre 19962005. Na última década aumentaram muito os trabalhos sobre vários aspectos da Geografia de Espanha (7 artigos entre 1996/2005 e 25 entre 2006-2015) e do Brasil ( 3 na primeira década, 9 na última, fig. 1b). Angola, inicialmente objecto de muitos trabalhos, sobretudo por parte de investigadores do CEG, que aí investigaram e leccionaram, deixou praticamente de estar representada a partir de 1985 (só um artigo na década 2006-2015). Pelo contrário, depois de um interregno, Moçambique foi representado com 5 artigos entre 2006 e 2015, França e Cabo Verde foram sendo esporadicamente contemplados.

Numa apreciação de base espacial mais ampla a Ásia ocupa sempre o último lugar e a América o penúltimo. As posições relativas da África, Europa e Península Ibérica alteraram-se no decurso do tempo: África estava à frente da Europa e da Península Ibérica, tanto entre 1966/1975 como entre 1976/1985, mas a partir de 1986 as posições relativas passam a ser Europa, seguida da Península Ibérica e da África. Para esta evolução terá pesado a descolonização por um lado, a integração de Portugal na União Europeia por outro e, ainda, a crescente globalização ${ }^{\mathrm{xx}}$. 


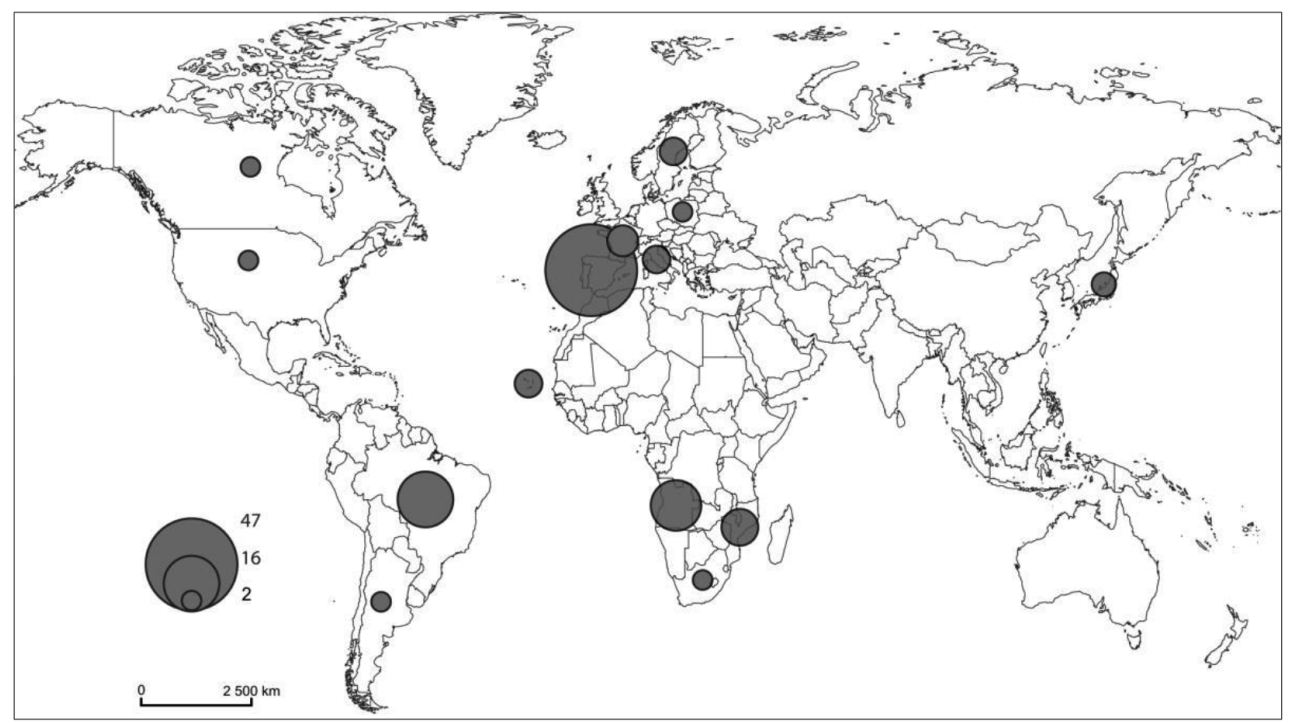

1 a)

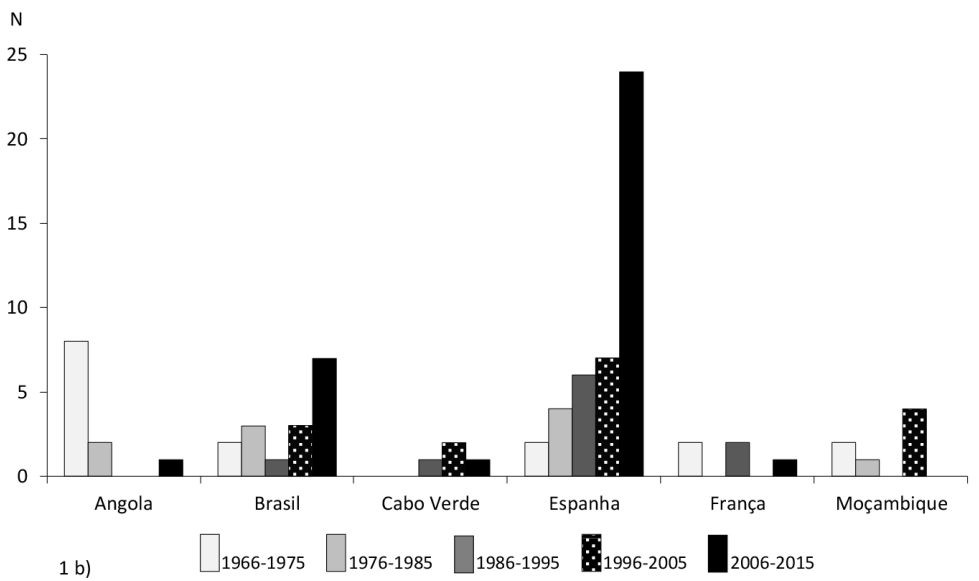

Fig. 1 - Âmbito espacial dos artigos da Finisterra:

a) Número total de artigos por país (tratado em mais de dois artigos), excluindo Portugal;

b) Número de artigos referentes aos países mais estudados, por década.

Fig. 1 - Spatial scope of articles in Finisterra:

a) Total number of papers referring to different countries, excluding Portugal;

b) Number of articles referring to the most studied countries, by decade. 


\section{Temas}

Os temas dos artigos foram analisados com base na classificação usada nos índices referidos anteriormente, que foi adaptada e reorganizada para tornar possível a comparação das diversas décadas. Vários items foram subdivididos para melhor espelhar a evolução (fig. 2). Note-se que as percentagens dos vários grupos temáticos são aproximadas, pois nunca se consegue eliminar completamente a subjectividade da classificação.

Nas 5 décadas em análise, os temas mais tratados foram de Geografia social e cultural com 72 artigos, seguidos de Geografia urbana, Climatologia e Geomorfologia com perto de 50. Foram publicados 30 artigos sobre Planeamento e desenvolvimento regional, 25 sobre Cartografia e Sistemas de Informação Geográfica e perto de 20 sobre Biogeografia e Conservação da Natureza, Geografia rural e Geografia regional.

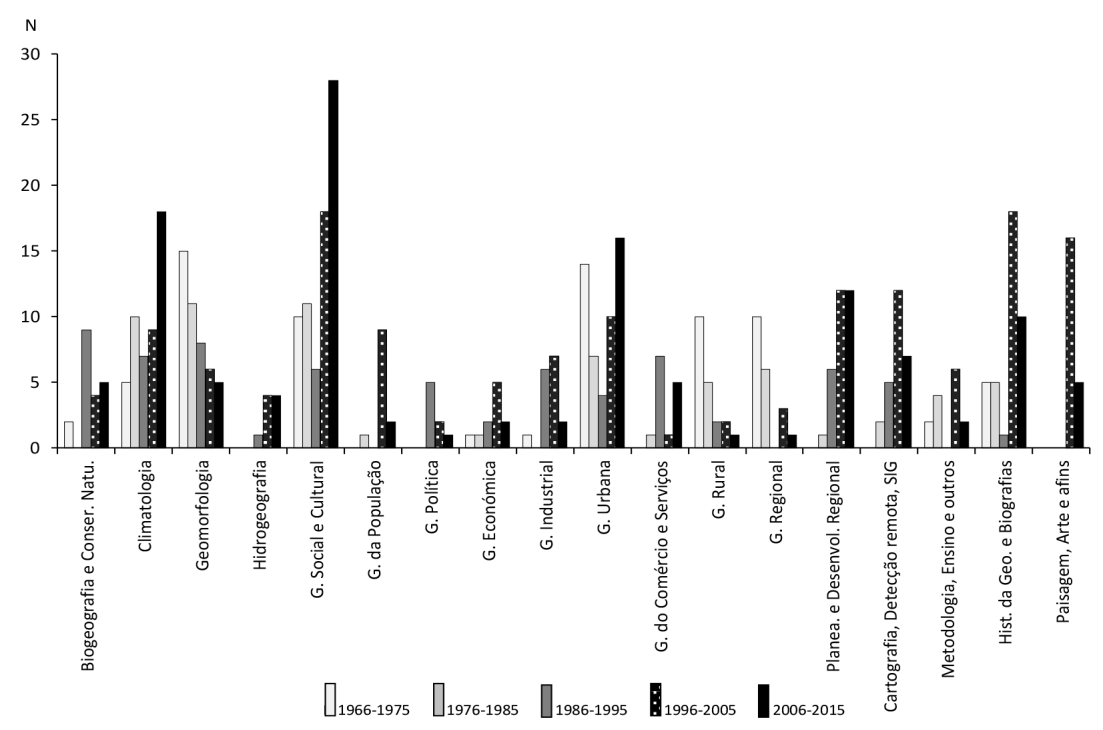

Fig. 2 - Temas tratados na Finisterra (número de artigos por década).

Fig. 2 - Subjects dealt with in Finisterra (number of papers by decade).

Será, no entanto, mais interessante, analisar-se a evolução por década da frequência dos vários temas tratados. No âmbito da Geografia física o número de artigos de Geomorfologia decresceu bastante. A sua importância nos primeiros números da revista estará relacionada com a longa tradição de estudos de Geomorfologia em Portugal

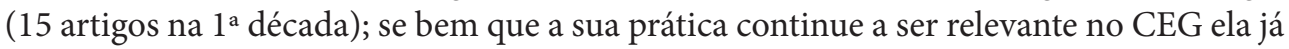
não está tão presente nos artigos submetidos à revista ( 5 na última década), o que se pode dever à selecção de outras revistas para publicação. Pelo contrário, a Climatologia, com presença modesta na altura do aparecimento da revista (5 artigos na primeira década), 
já que então era pouco praticada no CEG, foi adquirindo peso ao longo das décadas (18 na última). Biogeografia e Conservação da Natureza adquiriram mais relevância a partir de 1986, enquanto a Hidrogeografia, mais recente no CEG como tema independente da Geomorfologia, se desenvolveu nas duas últimas décadas.

No caso da Geografia humana, nas primeiras décadas sobressaem os estudos de Geografia urbana e Geografia social e cultural e, com menos artigos, Geografia económica, industrial e de comércio e serviços. Os artigos sobre Geografia da população são mais frequentes na década 1996-2005, diminuindo depois. Vão sempre surgindo artigos sobre temas que são novidade no meio geográfico português, como a Geografia política e investigações de natureza teórico-metodológica. Nos anos mais recentes, observa-se um grande aumento de artigos de Geografia social e cultural, de Geografia urbana, Planeamento e desenvolvimento regional e sobre a História da Geografia, onde se incluem textos sobre o pensamento geográfico.

Alguns temas começaram por ter grande expressão na revista, mas desapareceram quase completamente nos anos mais recentes (passaram de 10 para 1 artigo por década): Geografia rural e Geografia regional. A diminuição dos estudos de Geografia rural terá relação estreita com o recuo do peso da agricultura na economia portuguesa. A Geografia regional, ligada a uma suposta Geografia clássica da "escola regional francesa", foi durante décadas encarada como uma corrente ultrapassada por muitos investigadores do CEG. Ela foi substituída por uma Geografia mais moderna e aplicada, que teria expressão no grupo Planeamento e desenvolvimento regional. Quanto à Geografia política, os seus tempos áureos tiveram relação estreita com o período pós 25 de Abril de 1974, quando se começou a reflectir sobre as mudanças políticas e socias desencadeadas por esta revolução.

Os artigos de Cartografia, Detecção Remota e Sistemas de Informação Geográfica (SIG) aumentaram em número até à década 1996-2005, coincidindo com progresso no desenvolvimento dos de Cartografia e SIG, o que terá também relação com os dois números temáticos da Finisterra em 2003 (quadro VII). A Detecção remota era praticada no CEG desde a década 1980, o que se traduziu na publicação de alguns artigos (e também de notas, que não foram contempladas nesta estatística). O eclectismo da revista revela-se nos temas das colunas finais, pois no número temático sobre "Paisagem" e no presente sobre o "Espaço" (entre outros artigos mais "heterodoxos" que foram aceites devido ao seu interesse), foram publicadas contribuições que não se enquadram em qualquer das tipologias anteriores, mas que foram consideradas uma mais-valia. Por outro lado, houve números da revista, integral e intencionalmente dedicados a certos temas, ou a certas personalidades (quadro VII), que têm reflexos na distribuição dos temas tratados.

Nota-se que os números temáticos têm tido forte crescimento. Até 2000 (35 anos) publicaram-se apenas 8, dos quais 2 dedicados a fundadores da revista e 1 a Emmanuel de Martonne; depois desse ano (ou seja em 15 anos) houve 13 números temáticos, 4 dos quais com homenagens a 4 investigadores do CEG.

Os temas tratados na Finisterra revelam assim influências diferenciadas: i) o aparecimento de novas tecnologias que originam abordagens distintas (mudanças técni- 
cas mas também conceptuais ou de especialização temática); ii) o aparecimento de revistas internacionais de temáticas específicas e alterações no paradigma de avaliação científica; e iii) a importância dos números temáticos, muitos deles resultado de projectos de investigação, revelam a evolução temática da ciência geográfica a nível nacional e internacional.

Quadro VII - Números temáticos da Finisterra (1966-2015).

Table VII - Thematic issues of Finisterra (1966-2015).

\begin{tabular}{|c|c|c|}
\hline Ano e No & Responsáveis pelo No & Temas tratados ou investigador homenageado \\
\hline $1968(6)$ & O. Ribeiro; S. Daveau; I. do Amaral & 1 Seminário Internacional de Geografia \\
\hline $1973(16)$ & O. Ribeiro; S. Daveau; I. do Amaral & Emmanuel de Martonne \\
\hline $1975(20)$ & Jorge Gaspar & Lisboa \\
\hline $1994(57)$ & Teresa B. Salgueiro e C. Carreras & Evocação dos Jogos Olímpicos de 1992 em Barcelona \\
\hline $1996(62)$ & Jorge Gaspar & Geografia industrial e económica no CEG \\
\hline $1997(63)$ & Carlos Alberto Medeiros & Suzanne Daveau \\
\hline $1998(65)$ & Membros da Comissão PG, UGI & História do Pensamento Geográfico (PG) \\
\hline $1999(67 / 8)$ & Carlos Alberto Medeiros & Ilídio do Amaral \\
\hline $2001(72)$ & $\begin{array}{l}\text { M. João Alcoforado } \\
\text { e Margarida Queirós xxi }\end{array}$ & Orlando Ribeiro (35 anos da revista) e A Paisagem \\
\hline $2003(75 / 6)$ & $\begin{array}{l}\text { Direcção e Comissão de Redacção } \\
\text { da Finisterra e D. Abreu }\end{array}$ & Sistemas de Informação Geográfica (SIG) \\
\hline $2004(77)$ & M. Lucinda Fonseca e Russel King & Migrações na bacia mediterrânea \\
\hline $2005(79)$ & M. João Alcoforado, Directora & Carlos Alberto Medeiros \\
\hline $2006(81)$ & Teresa Barata Salgueiro & $\begin{array}{l}\text { Cidades, contributos Área Investigação Geog. Hum. } \\
\text { e Regional }\end{array}$ \\
\hline $2008(85)$ & Suzanne Daveau & Conferencistas nos Colóquios da Biblioteca Orlando Ribeiro \\
\hline $2008(86)$ & Carlos Alberto Medeiros (coord.) & A. Machado Guerreiro (parte do n. ${ }^{\circ} 86$ ) \\
\hline $2009(87)$ & Gonçalo Vieira e Carla Mora & $\begin{array}{l}\text { Ambientes frios plistocénicos e actuais/Iberian Research } \\
\text { on Pleistocene and present-day cold environments }\end{array}$ \\
\hline $2009(88)$ & Mário Vale & $\begin{array}{l}\text { Conhecimento, Inovação e Território/Knowledge, } \\
\text { Innovation and Territory }\end{array}$ \\
\hline $2010(90)$ & Margarida Queirós & Barcelona(s) \\
\hline $2012(94)$ & Isabel André & $\begin{array}{l}\text { Estratégias territoriais criativas/Territorial Creative } \\
\text { Strategies }\end{array}$ \\
\hline $2013(96)$ & M. Lucinda Fonseca e J. McGarrigle & $\begin{array}{l}\text { Neighbourhood integration, social relations } \\
\text { and participation in European multi-ethnic cities }\end{array}$ \\
\hline $2014(98)$ & M. João Alcoforado & Henrique Andrade. Applied Human Bioclimatology \\
\hline $2015(100)$ & $\begin{array}{l}\text { Direcção e Comissão Executiva da } \\
\text { Finisterra }\end{array}$ & 50 anos da Revista e O Espaço \\
\hline
\end{tabular}




\section{Os autores}

Enquanto nos primeiros anos da Finisterra, a Direcção precisava de procurar quem nela publicasse, vive-se agora a situação oposta, com grande afluxo de textos, sendo maior a dificuldade de contar com revisores científicos de qualidade e com disponibilidade. Como se referiu, tem havido grande afluxo de submissões por autores estrangeiros. Salientem-se os casos de Espanha, França e Brasil. No entanto, a nacionalidade dos autores variou muito ao longo dos anos. Por exemplo, como se observa na figura 3 , a participação de autores franceses sempre ocorreu, sendo máxima (18\%) na década 1996-2005 e decrecendo para $4 \%$ na década mais recente. No período inicial tinha atingido $10 \%$. Pelo contrário, a presença de autores espanhóis aumentou regularmente ao longo do tempo, até alcançar $42 \%$ entre 2006 e 2015. Isso é apenas parcialmente devido a um número temático (n ${ }^{\circ}$ 90, quadro VII). Nota-se também um aumento progressivo de autores brasileiros na Finisterra ( $14 \%$ na última década). Os autores publicados de outras nacionalidades decresceram na última década.

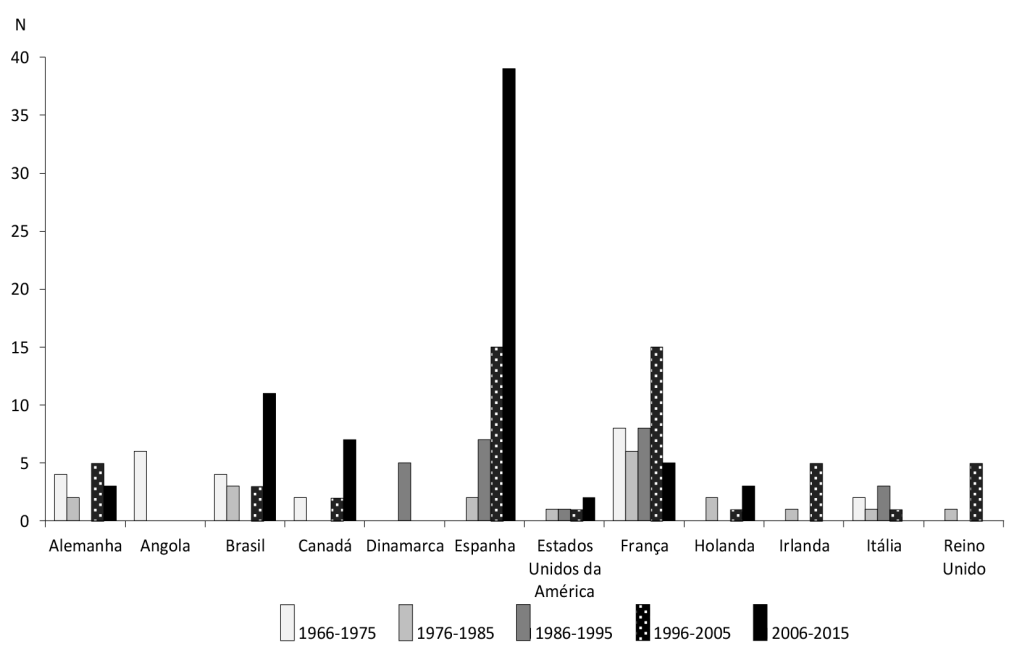

Fig. 3 - Número de artigos da Finisterra, por país de afiliação dos autores, por década.

Autores afiliados em universidades portuguesas excluídos (67\% do total).

Fig. 3 - Number of papers in Finisterra, per authors' country affiliation, by decade. Authors affiliated to a Portuguese university excluded (67\% of total). 


\section{Idiomas de publicação}

Como se referiu, a Finisterra recebeu, desde o início, a colaboração de investigadores estrangeiros. A língua estrangeira dominante foi indiscutivelmente o francês até aos meados da década de 1990, tornando-se depois mais esporádico (fig. 4). O inglês passou então a ser a língua estrangeira dominante. Apesar disso são poucos os ingleses, ou outros anglo-saxónicos, a submeter artigos (fig. 3), à excepção de alguns números temáticos. Publicam em inglês tanto alemães, como nórdicos, asiáticos e, desde há alguns anos, também portugueses e espanhóis. Isso significa que não se pode estabelecer ligação directa entre nacionalidade dos autores e língua de edição. Esta situação prender-se-á com o facto de actualmente a ciência de vanguarda e referenciada nos índices internacionais mais conceituados, se exprimir maioritariamente em inglês. Assim, apesar de o português ser a língua dominante, nas últimas duas décadas tem evidenciado uma diminuição em prol do inglês (fig. 4). O espanhol tem estado representado com percentagens bastante irregulares. Nos anos mais recentes ele iguala, ou supera mesmo, o inglês em certos anos (por exemplo, 2010), enquanto o italiano tem presença residual (um artigo em 1977 e outro em 1989).

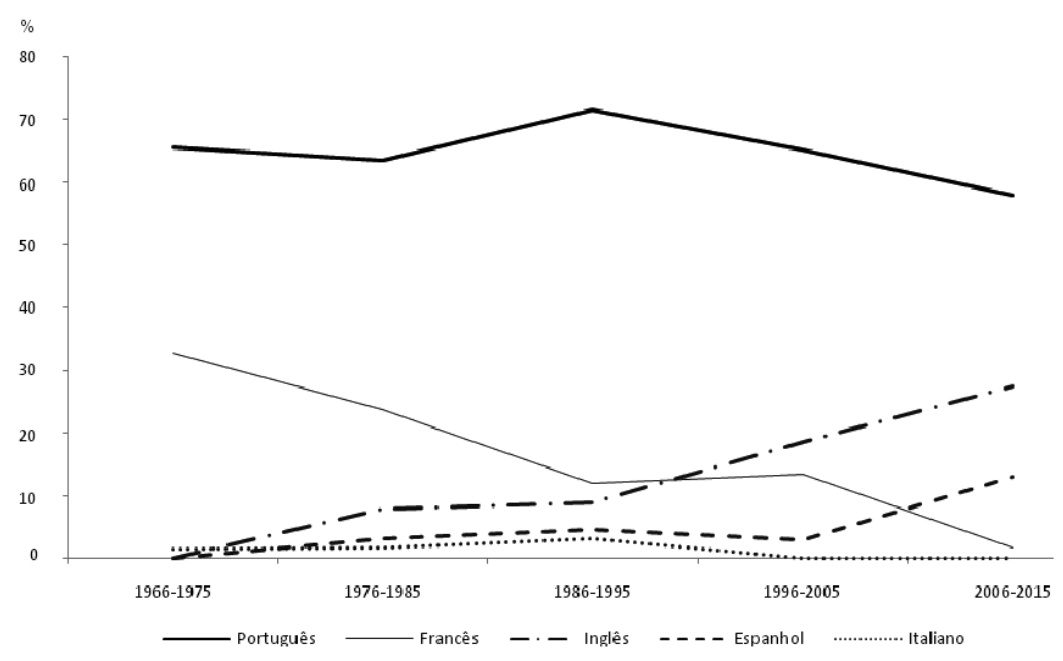

Fig. 4 - Artigos da Finisterra em diferentes idiomas por década (\%).

Fig. 4 - Finisterra's papers in different languages by decade (\%).

\section{Resumos}

Nos primeiros números da revista, os resumos não eram obrigatórios, embora fossem frequentes. Não havia resumos na língua do próprio texto, fosse ele português ou francês 
(as duas línguas então dominantes), já que o francês era conhecido e praticado por todos portugueses instruídos e tinha forte presença na Europa. Ou seja, até à década de 1970, na Finisterra só apareciam resumos em francês, para os textos escritos em português (a maioria) ou noutra língua. O primeiro resumo em inglês apareceu no n. ${ }^{0} 9$ (1970) num texto de Mariano Feio. A primeira excepção à regra de um só resumo acontece com o artigo de Orlando Ribeiro sobre Emmanuel de Martonne, escrito em francês, com resumo nesta língua e em inglês no n. ${ }^{0} 16$ (1973). Talvez a intenção de dar a conhecer a um largo público a obra do seu mestre e amigo tivesse pesado na decisão. Embora desde 1970 começasse a ser frequente a presença de resumos duplos, em francês e em inglês, só em 1974 o uso das duas línguas passa a ser regra. Resumos em português só esporadicamente figuraram antes do n. ${ }^{0} 35$ (1983) e resumos sistemáticos na língua em que o texto é publicado só ocorrem a partir de 1991. O número de resumos em línguas diferentes cresce muito a partir de 1996. As línguas sistemáticas e obrigatórias são o português, o francês e o inglês. A língua espanhola marca presença crescente nos últimos anos e, nos últimos números da revista, surgiram resumos em árabe e em chinês, fruto da crescente procura de artigos publicados na Finisterra, por falantes destas línguas.

\section{Ilustrações}

Ao longo dos seus 50 anos de existência, a Finisterra registou mudanças assinaláveis no modo como a expressão gráfica se tem efectuado. A figura 5 parece desmentir a tendência actual de valorização da imagem.

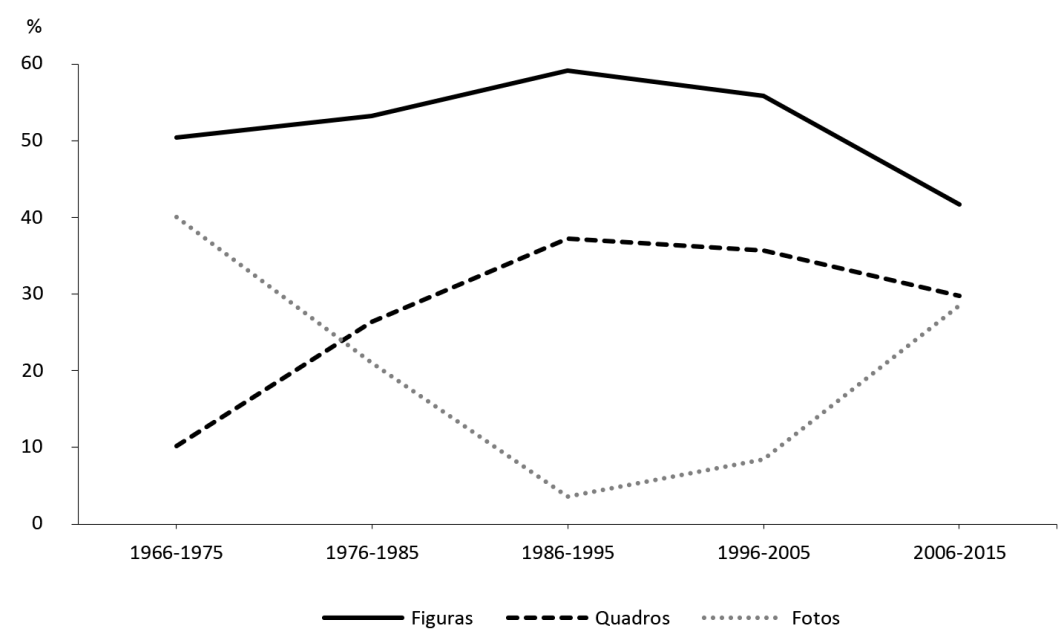

Fig. 5 - Ilustrações dos artigos da Finisterra por década (\%).

Fig. 5 - Illustrations within Finisterra's papers by decade (\%). 
Na Finisterra, o número de figuras (mapas e gráficos) variou pouco ao longo do tempo (cerca de $50 \%$ da infografia, fig. 5), tendo, no entanto, sofrido uma recessão na última década (desceu para 40\%). A evolução registada tem naturalmente relações estreitas com as mudanças na maneira de elaborar mapas e gráficos e o fim da secção de desenho do CEG. Apesar do actual uso generalizado de software de desenho, o número de figuras não terá aumentado por várias razões: as exigências de qualidade e rigor da Finisterra em relação às peças gráficas leva a que muitos autores tomem outras opções (por exemplo, apresentação de quadros); a Finisterra, no seu formato analógico, só publica a preto e branco, tornando ilegíveis algumas das figuras enviadas e, embora a versão online possa ter ilustração a cores, isso exige um aumento do consumo de tempo dos autores na execução gráfica e o domínio de softwares avançados. $\mathrm{Na}$ Finisterra procura-se, em concordância com os autores, que os mapas e outras figuras que ilustram os textos submetidos apresentem melhor qualidade gráfica e cartográfica possível. Os quadros têm vindo a crescer: de 10 para 30\%, com um aumento maior nas três primeiras décadas. Descida mais precoce e acentuada ocorreu no que diz respeito às fotografias, cuja presença, nos primeiros anos da revista era constante, forte e de qualidade, provavelmente sob o incentivo de Orlando Ribeiro, grande fotógrafo, e dos colegas da sua geração. O fulgor da imagem nos mais diversos campos e a facilidade da sua aquisição talvez tenha levado os investigadores a voltar a utilizá-la como ferramenta geográfica (as fotografias passaram de 5\% na década de 1986-95 para quase 30\% entre 2006 e 2015).

\section{BALANÇO E PERSPECTIVAS}

Neste já longo percurso da Finisterra é possível distinguir períodos com características diferentes.

Entre 1966-1975, a fase de lançamento foi marcada pela decisão de criar uma revista de Geografia portuguesa. Poucos investigadores do CEG tinham experiência em colaborar com revistas, e os geógrafos universitários eram muito poucos. Acresce que, nesse período, a Geografia viveu uma fase de mudança de paradigma, de que o aspecto mais saliente foi, porventura, a tentativa de afirmação da chamada Nova Geografia, opondo-se à chamada Escola Regional Francesa. No entanto, todos os investigadores do CEG colaboravam na revista, qualquer que fosse a sua perspectiva face à Geografia. O confronto de ideias e a liberdade de as manifestar estão patentes nos artigos publicados. Os textos da revista foram neste período dominados pela Geomorfologia, que os três directores praticavam, e também pela Geografia regional e rural. Portugal era então um país muito marcado pela ruralidade e a escola regional francesa, bem como a bibliografia em francês, dominavam em Portugal.

Seguiram-se duas décadas (1976-1994) de consolidação. Em 1986 cria-se a Comissão de Redacção, órgão consultivo com 6 doutores, todos investigadores do CEG. O conteúdo da revista também sofre alterações, por exemplo nas línguas estrangeiras de consulta 
bibliográfica e nas línguas dos resumos. O francês, dominante até então, primeiro coexiste com o inglês, mas depois cede a primazia. Os temas dominantes nos artigos também se alteram: diminui a presença da Geografia rural e da regional. Os estudos climáticos sobressaem, mantendo a Geomorfologia lugar de destaque. Os artigos mais ligados aos aspectos humanos da Geografia cobrem áreas extremamente variadas. Sobressai o grande conjunto Geografia urbana, Geografia económica, Geografia do comércio e serviços, Geografia industrial e aparecem temas que são novidade no meio geográfico português, como a Geografia política e investigações de natureza teórico-metodológica. Certos aspectos de natureza gráfica começam a mudar na revista: ainda que a capa continue praticamente inalterada, mudam os tipos de ilustrações: as fotografias diminuem fortemente e a presença de mapas e de gráficos torna-se bastante flutuante.

O período entre 1995-1999 foi de numerosas alterações estruturais. Em 1995, foi criado o primeiro órgão consultivo externo, com 13 investigadores que não eram membros do CEG, 6 dos quais estrangeiros. No mesmo ano muda a estrutura de apresentação dos textos, com o desaparecimento dos "Elementos Estatísticos", que alternavam com a rubrica "Documentos para o Ensino", e a sua substituição pela secção "Notícias". Também as "Notas" foram autonomizadas das "Recensões". As "Normas de Publicação", que existiam desde 1992 em português, passaram em 1998 a figurar também em inglês. Todos os títulos de figuras e de quadros passam a ser traduzidos para inglês em 1995, qualquer que fosse a língua de publicação. Deu-se também início a novo processo de apreciação da qualidade de textos, que seria aprofundado e melhorado nos anos seguintes. De facto, a Comissão Editorial criada em 1995, em substituição do Conselho de Redacção, tinha passado a incluir, de forma automática, todos os investigadores que concluíssem o doutoramento. O elevado número de membros deste órgão, bem como o aumento do número de textos submetidos, obrigariam a breve trecho a profundas alterações, para que a qualidade científica da revista pudesse ser mantida.

Observa-se um grande aumento de artigos de Geografia social e cultural e toma preponderância a História da Geografia, onde se incluem textos sobre o pensamento geográfico. Entre 2000 e 2015, aposta-se na estandardização de procedimentos e na difusão em acesso aberto. As grandes mudanças num mundo que se diz globalizado tiveram repercussões na Finisterra. A colocação de todos dos artigos online, desde o primeiro número da revista xxii, para consulta sem qualquer reserva, levou naturalmente à sua ampla divulgação. A ubiquidade da internet veio permitir uma maior visibilidade. O empenho colocado na integração da revista no maior número possível de listas de indexação - presentemente a Scielo Citation Index, Scopus, WebQualis (Capes A2), DOAJ, Dialnet, Ebsco e Latindex -, é uma exigência do meio académico, que é tão imperiosa quanto vantajosa acatar. Na revista publicam não só membros do CEG, mas também investigadores nacionais e estrangeiros de outros Institutos e Universidades, muitos deles em inglês, língua que passou também a ser escolha frequente dos autores de diversas nacionalidades. Nesta última década nota-se grande incremento de artigos de Geografia social e cultural (30), mas também de Planeamento e desenvolvimento regional, Geografia urbana e de Climatologia. 
A preservação da qualidade científica tem sido uma preocupação constante. Do elevado número de textos submetidos, nos últimos 10 anos foram aceites cerca de $60 \%$, alguns dos quais após modificações "substanciais" solicitadas aos autores. O período de tempo que decorre entre a chegada de um texto e a sua aceitação final (de conteúdo e formal) depende de muitos factores, mas o objectivo dos actuais órgãos executivos é diminuir cada vez mais este lapso de tempo. Não é demais salientar o trabalho dos revisores científicos, que contribuem para a qualidade dos textos publicados. Na tentativa de modernização dos processos de edição da revista, aliás à semelhança de outras revistas internacionais, utiliza-se a plataforma (RCAAP ${ }^{\text {xxii }}$ ) para submissão dos artigos e diálogo com autores e revisores.

As páginas da Finisterra ficaram desde o início "abertas a todos os que, entre nós, cultivem estudos geográficos ou matérias afins, na margem necessariamente imprecisa, em que as Ciências se tocam, se recobrem e se confundem" (Ribeiro, 1966: 5). Foi a vontade, o empenho e a dedicação das sucessivas direç̧ões, de todos os colaboradores e de todos os que nela publicaram ao longo dos seus 50 anos de existência, que permitiu não apenas a existência mas sobretudo a evolução e modernização da Finisterra, que procura manter o interesse, o rigor científico e a inovação nos textos publicados. Passados 51 anos após a sua fundação, inicia-se uma nova etapa da vida da Finisterra. Parafraseando novamente Rúben A. podemos afirmar com conviç̧ão "o geógrafo não cansa, avança”" (Diário Popular, 20-2-1969).

O ponto mais ocidental da Europa chegou a ser considerado o Cabo Finisterra na Galiza $\left(42^{\circ} 55^{\circ} 28^{\circ} \mathrm{N}, 9^{\circ} 17^{\circ} 29^{\circ} \mathrm{W}\right.$, ou em coordenadas decimais lat. 42.883333; long. -9.26666), mas na realidade é o Cabo da Roca em Portugal, cerca de 16,5 km mais a oeste $\left(38^{\circ} 47^{\circ} 0^{\circ} \mathrm{N}, 9^{\circ} 30^{\circ} 0^{\circ} \mathrm{W}\right.$, ou lat. 38.783333 ; long. -9.5$)$.

ii Veio a descobrir-se que, em 1989, fora criada outra revista chamada Finisterra. Uma revista de reflexão e crítica. Como a Finisterra geográfica nunca se tinha preocupado com o registo do título e o promotor da revista literária, Eduardo Lourenço, desconhecia a existência de outra Finisterra, esse nome foi por ele escolhido e formalmente registado. Só em 1991 a Finisterra. Revista Portuguesa de Geografia conseguiria registar este título, felizmente sem ter de o alterar, por se ter atendido ao subtítulo.

iii Uma das mais antigas é o Boletim da Sociedade de Geografia de Lisboa, com início em 1876. O Boletim do Centro de Estudos Geográficos de Coimbra foi publicado entre 1950 e 1967, substituído só em 1983 pelos Cadernos de Geografia. Outras revistas científicas com publicação regular são a Biblos da Universidade de Coimbra, desde 1927, e a Análise Social do Instituto de Ciências Sociais, a partir de 1963. Os Serviços Geológicos divulgam o Boletim da Sociedade Geológica de Portugal desde 1941, e as Comunicações dos Serviços Geológicos de Portugal desde 1947, edições que deveram muito à iniciativa de Carlos Teixeira, contemporâneo e amigo de Orlando Ribeiro. A revista Garcia da Orta, publicada pela Junta das Missões Geográficas e de Investigações do Ultramar (depois Instituto de Investigação Científica Tropical), teve início em 1953. De entre as revistas de Geografia estrangeiras mais antigas, contam-se Die Erde, editada na Alemanha desde 1853, a Geographical Review, publicada nos Estados Unidos desde há precisamente um século (substituindo o Bulletin of the American Geographical Society, fundado em 1859) e as Annales de Géographie, difundidos em Paris desde 1891.

iv Amaral, I. do (2001) - Finisterra. Uma revista com 35 anos de prestígio. Finisterra-Revista Portuguesa de Geografia, XXXVI(72):11-25.

v Entre 1992 e 1994 (números 53/54 a 58) a coordenadora, Maria João Alcoforado, foi designada "secretária"; as outras pessoas que com ela colaboravam eram membros do "secretariado".

vi A lista com todos os nomes está registada no n. ${ }^{\circ}$ 59/60 de 1995.

vii Substituído por Herculano Cachinho no n. ${ }^{\circ} 92$ (2011).

viii Substituído por Isabel Margarida André no n. 91 (2011).

ix Os 2 investigadores obrigatoriamente consultados para fazerem a avaliação podem pertencer ou não à "Comissão Editorial Externa”. A decisão depende da disponibilidade dos investigadores consultados (que por vezes recusam ou, o que é pior, não respondem) 
e da tentativa de se escolher o melhor especialista familiarizado com o tema e a língua em que o texto é submetido. Este modo de proceder segue de perto o processo adoptado por grande parte das revistas científicas que integram as mais prestigiadas listas de indexação, em muitas das quais a Finisterra passou a figurar, como se regista na contracapa.

x Rute Vieira, licenciada em Geografia pela Faculdade de Letras da Universidade de Lisboa e bolseira da FCT trabalha a tempo parcial para a Finisterra. O tempo de que dispõe é escasso para as tarefas que lhe competem. Esta sobrecarga tem vindo a aumentar com o incremento acentuado de textos submetidos e com a integração da revista em várias indexações internacionais.

xi As instituições que deram apoio financeiro estão indicadas na contra-capa.

xii Alcobacense (1966-1991); Colibri (1992-1998); Barbosa e Xavier (1999-2005); Textype (2006-2010); Europress (2011-2015).

xiii Exclui-se o número 53/54 (1992) onde não figura a distribuidora.

xiv O DOI é o identificador de documentos disponíveis online, que surge com a necessidade de segurança dos objectos, especialmente publicações em revistas e obras protegidas por copyright, muitas das quais localizadas em bibliotecas virtuais. A grande vantagem deste identificador prende-se com o facto de os objectos digitais se tornarem únicos e acessíveis, independentemente das configurações de rede, mudanças no nome do servidor ou até a sua extinção. Adicionalmente, o "registo" de propriedade é imediatamente atribuído não estando sujeito a atrasos ou problemas de publicação na edição em formato analógico.

xv A partir de 2012 desaparece a rubrica "notas", mantendo-se no restante a organização de 2011.

xvi Instituto de Geografia e Ordenamento do Território, Edifício IGOT - Rua Branca Edmée Marques 1600-276 Lisboa, Portugal.

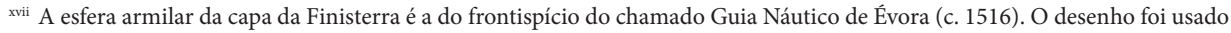
sobre fundo cinzento de 1966 a 1994, (n. ${ }^{\circ}$ 1-52) e sobre fundo azul (capa de Pedro Calapez) a partir de 2003 (n. ${ }^{\circ}$ 75) até ao presente. Entre 1995-2002 (n. ${ }^{\circ}$ 53/54-74), o desenho da esfera ficou diluído num painel de azulejos existente no Palácio da Pena, em Sintra. (capa de A. Lopes).

xviii O n. 77 (2004) apresenta o seguinte Sumário: “Articles, Notes, Book Reviews, News".

xix O que se deve, em parte, a ter-se passado a usar o mesmo tipo de letra em todo o número, quando até então os artigos tinham corpo maior do que as restantes rubricas.

xx Com a colaboração de Paulo Morgado, João Vasconcelos, Jorge Trindade e Ricardo Garcia, além do apoio da Biblioteca Nacional de Portugal, Fundação da Universidade Lisboa e Faculdade Letras da Universidade de Lisboa.

xxi Tendo-se começado por disponibilizar os números mais recentes, foi-se progressivamente recuando e, em finais de 2011, todos os artigos estavam on-line com acesso aberto a toda a comunidade.

xxii A Finisterra foi uma das 10 revistas portuguesas seleccionadas para fazer parte do "RCAAP" (Repositório Científico de Acesso Aberto de Portugal), promovido pela UMIC - Agência para a Sociedade do Conhecimento e operacionalizado pela Fundação para a Computação Científica Nacional (FCCN) [http://projecto.rcaap.pt/index.php/lang-pt/sobre-o-rcaap/enquadramento] com o apoio da Universidade do Minho. http://revistas.rcaap.pt/finisterra/ 